\title{
Retracted Article: Performance benefits of regeneration flexibility and modulation convertibility in elastic optical networks
}

\author{
Sridhar Iyer ${ }^{1}$
}

Published online: 2 March 2018

(C) Springer Science+Business Media, LLC, part of Springer Nature 2018

The Editor-in-Chief has retracted this article. Recently, a reader of Telecommunication Systems brought to our attention that some parts of this article [1] have been plagiarized from another publication [1] without giving a citation or credit. After investigating this case, it was confirmed that this paper duplicates Figs. 1, 2 and Tables 1, 2, and larger part of the text from [1]. Hence, the editorial team and publisher have determined that it should be retracted from the journal. The author disagrees with the retraction.
The online version of this article contains the full text of the retracted article as electronic supplementary material.

[1] Klinkowski, M., \& Walkowiak, K. (2016). On performance gains of flexible regeneration and modulation conversion in translucent elastic optical networks with superchannel transmission. Journal of Lightwave Technology, 34(23), 5485-5495. https://doi.org/10.1109/JLT.2016.2621882.
Electronic supplementary material The online version of this article (https://doi.org/10.1007/s11235-018-0432-6) contains supplementary material, which is available to authorized users.

\section{Sridhar Iyer}

sridhariyer1983@gmail.com

1 Department of ECE, Jain College of Engineering, T S. Nagar Hunchanatti Cross- Machhe, Belagavi, Karnataka 590014, India 